\title{
Keeping the faith: Receptiveness, capacity and acceptability of Islamic religious settings to deliver childhood obesity prevention intervention
}

\section{Sufyan Abid Dogra ( $\square$ Sufyan.Dogra@bthft.nhs.uk)}

Bradford Institute for Health Research https://orcid.org/0000-0001-9896-9503

\section{Kiran Rai}

University of Birmingham

\section{Sally Barber}

Bradford Institute for Health Research

\section{Rosemary RC McEachan}

Bradford Institute for Health Research

\section{Peymane Adab}

University of Birmingham

\section{Laura Sheard}

Bradford Institute for Health Research

\section{Research}

Keywords: Islamic religious settings, childhood obesity prevention, intervention design and delivery, health and religion, intervention acceptability, qualitative applied health research

Posted Date: March 12th, 2020

DOI: https://doi.org/10.21203/rs.3.rs-17023/v1

License: (c) (i) This work is licensed under a Creative Commons Attribution 4.0 International License. Read Full License 


\section{Abstract}

Keeping the faith: Receptiveness, capacity and acceptability of Islamic religious settings to deliver childhood obesity prevention intervention

Background: Childhood obesity rates among South Asian populations in the UK are significantly high. $10 \%$ of childhood population in the UK are of South Asian origin, majority of them follow Islamic faith and attend Islamic religious settings (IRS) daily after school. IRS may be appropriate channels for obesity prevention initiatives; however there is limited evidence for this approach.

Methods: Using a qualitative research methodology, we conducted 20 indepth interviews with parents of 5-11 years old children attending IRS, 20 indepth interviews with Islamic leaders, and 3 focus group discussions with 26 managers and workers of IRS in Bradford and Birmingham in the UK. The guides for interviews and focus groups, tailored to each group of participants, were developed from a literature review and prior learning from the results of other work packages in the same study. Interviews and focus group discussions were audiorecorded, transcribed, and analysed thematically.

Results: IRS are receptive to delivering a childhood obesity prevention intervention. Most of them have the capacity and the delivery would be acceptable to parents of children attending these settings. All participants viewed Prophet Muhammad's physical fitness, food and his attitude towards physical activity and maintaining healthy lifestyle as the best role model to follow. Managers and workers in IRS showed willingness to conduct physical activity sessions for South Asian boys and girls and emphasised the need to have female instructors and role models to encourage South Asian girls. Practical barriers for the intervention delivery were poor funding systems and time constraints for managers and workers.

Conclusion: IRS can deliver childhood obesity prevention interventions. Interventions should be co-designed, culturally/religiously sensitive and combine the scientific guidelines on healthy living with Islamic narrative on importance of physical activity and healthy diet consumption and should involve local place-based groups for delivery.

\section{Background}

Obesity in children is associated with physical, social and psychological health problems, and tracks to adulthood, with subsequent increased risk of chronic diseases(1-3). 40\% of South Asian (mainly Pakistani and Bangladeshi) children (aged 10-11 years) in the UK are overweight or obese compared with $32 \%$ within White British children (4). Ethnic inequalities in obesity in the UK result from a combination of metabolic, socioeconomic, cultural and behavioural factors $(3,5)$, with social and environmental factors contributing the most (6).

Dietary practices tend to be less healthy in South Asian young people and second generation migrant families (7). Substantial differences in dietary habits start from infancy, with higher sugar and fat content of foods introduced at weaning in Pakistani compared to white British infants (8). South Asian girls are more likely to skip breakfast and consume more sweetened drinks than their white British counterparts (9). Halal (Islamically permissible) food and meat products are an essential aspect of the diet for South Asian Muslims (10) limiting 
their food purchasing choices. Average consumption of fruits and vegetables is also lower among the South Asian populations compared to the white British population (11). Low levels of physical activity among South Asian children, particularly girls, is another important contributor to childhood obesity (12). Cultural practices and beliefs, such as preference for driving instead of walking (13) account for some of this behaviour. South Asian children and families are geographically concentrated in deprived areas (14) which further increases risk of childhood obesity. Interventions to enhance physical activity levels of South Asian children in the UK are lacking (15). To our knowledge, only five studies worldwide have tested the effectiveness of obesity prevention programmes in this population (16). These programmes were based in schools with little or no parental involvement and had mixed results (16). Parental and family involvement is particularly important in younger children (13). Obesity prevention programmes for children outside of the school settings have not been explored as much, and may be more promising.

Over two-thirds of British Muslims are of South Asian origin (17). 91\% of South Asian Muslim children in the UK go to a mosque or a madrassa (supplementary schools for Islamic learning) after school for Islamic education on some or most days of the week (18). Islamic religious settings (IRS) such as mosques, madrassas or women's circles to study Islam can be useful venues for targeting South Asian minorities to encourage healthy life styles (19-22). IRS in the UK are often voluntarily involved in health promotion and are feasible settings for the delivery of an obesity prevention intervention. Their potential can be harnessed if approached with keeping cultural and religious sensitivities in mind and if supplemented with Islamic narrative on obesity prevention (23). Previous research using this approach in relation to smoking cessation has proven to be acceptable and feasible (24-26). However, to date there is limited evidence on whether a similar strategy could be useful in relation to childhood obesity prevention. We acknowledge the complex and often negotiated relationship that Islamic leaders and communities have with interpreting and approving or disapproving certain health interventions and practices for Muslims $(13,20,23,27)$. However, there is uncertainty on how a health promotion intervention can be delivered by using or involving IRS. The current study addresses this knowledge gap and dearth of literature. The aim of our study was to investigate the receptiveness, capacity, and acceptability of delivering a childhood obesity prevention intervention using Islamic religious settings in the UK.

\section{Methods}

We used a qualitative research methodology. Our methods were indepth interviews and focus group discussions and our analysis was thematic. We took an inductive approach where the aim was for the findings to arise from the voices of participants. As such, we did not apply an existing theoretical framework to the dataset.

\section{Participants}

In order to grasp the receptiveness and capacity of IRS to deliver childhood obesity prevention interventions, we conducted 20 in depth interviews with Islamic leaders and 3 focus group discussions with IRS workers/managers $(n=26)$. To determine the acceptability of interventions within IRS for parents, we conducted another 20 indepth interviews with parents of children (5-11 years old) attending IRS. Ethical approval was obtained from research ethics committee of University of Bradford, UK (E645). 
We recruited research participants from two English cities with a high density of South Asian Muslim population, Bradford (24\%) and Birmingham (22\%). Research participants were recruited from three categories of people (Islamic leaders, IRS workers/managers, and parents of children attending madrassa). Purposive sampling sought to include participants with a range of markers of identity like geographical location (Bradford, Birmingham), sex (male, female), ethnicity (Pakistani, Bangladeshi), place of birth (UK or abroad), and first language (English or others).

\section{Researchers and language:}

The interviews and focus group discussions were conducted by two researchers (SD and KR). SD is male, fluent in Punjabi, Urdu, Arabic, Persian, and English, and based in Bradford. KR is female, fluent in Punjabi and English, and based in Birmingham. SD conducted interviews with most male participants and KR with mainly female participants in order to facilitate access. All interviews and focus group discussions were conducted in English as this was preferred by participants. Participants used words in Arabic, Urdu, and Punjabi while responding in English, particularly while discussing Islamic rituals or South Asian food habits.

\section{Indepth interview and focus group conduct}

A topic guide was used. It was developed from a literature review and prior learning from other work packages in the same study, including a scoping review and mapping exercise (23). The topic guides were tailored to each participant group (parents, Islamic leaders, IRS managers and workers) but had substantive components which were similar throughout. We focused on examining attitudes and beliefs in relation to: physical activity, healthy dietary habits, sleep/sedentary time and structural/organisational changes within IRS, and tailored topic guide after team discussed findings from initial interviews. All participants gave written, informed consent to take part in the study. Indepth interviews and focus group discussions were audio recorded and transcribed verbatim. Pseudonyms were used during transcription and data analyses. The duration of indepth interviews was 45-60 minutes and 60-90 minutes for focus groups.

\section{Analysis}

Thematic data analysis (28) followed five stages: data familiarisation, theme identification, indexing, charting and mapping the data. NVivo 12 was used to organise coding. SD, KR, SB and LS collaboratively developed the coding framework. SD coded four transcripts against the coding framework. SD, KR and LS fitted the data against the codes and designed the final framework of codes and sub-codes, then iteratively modified it. After discussing how the data fitted against the codes, we agreed on the final framework of codes and sub-codes for other transcripts.

During coding of interviews, we were aware of overt saturation and repetition of responses from participants. Therefore, the research team decided to code half (20 out of 40 ) of the indepth interviews transcripts and all 3 focus group transcripts in Nvivo and then read the rest of the transcripts (remaining 20 interviews), only explicitly coding if data was discordant. We ensured that the interview transcripts selected for coding were representative of the dataset as a whole by taking an equal sample from Bradford and Birmingham and an equal split of parents and Islamic leaders, and male and female participants.

\section{Results}


Overall, Muslim parents in Bradford and Birmingham informed us that an obesity prevention intervention using IRS would be acceptable to them. Islamic leaders and IRS workers were receptive to the idea of intervention in these settings and explained that IRS would have capacity for delivery. However, willingness to engage with an IRS based intervention had certain caveats. We explored the dominant moderating factors which influence acceptability, receptivity and capacity through three main overarching themes which arose from the data. These moderators are:

1. The importance of Islamic narrative

2. The influence of cultural context

3. Practical barriers and facilitators regarding implementation

Suggestions put forward by participants as to how the intervention could be practically enacted are detailed in appendix 1 .

\section{The importance of Islamic narrative}

We learned that the life of The Prophet Muhammad, his physical fitness and his daily routine, as it is communicated in mosques to British Muslims and taught to South Asian children in madrassas, is strongly viewed by participants as a perfect role model. The Islamic narratives on his food habits, sleeping patterns and physical fitness is understood as an embodiment of living an ideal healthy life. Parents, Islamic leaders and both male and female workers of IRS unanimously expressed their strong belief that children can learn about avoiding sedentary behaviours and taking up healthy eating if stories about the Prophet are recounted in interesting ways. "I would feel relieved, happy and enthusiastic if my child will come home from madrassa and say, "mum, this is healthy eating, that is not, our Prophet used to eat this food or that" (mother, Bradford). Participants mentioned that the best way to encourage people to avoid eating junk food and/or adopt healthy dietary habits is to introduce food items in their kitchen that Prophet Muhammad used to eat. "The simple diet, like dates and vegetables that Prophet Muhammad ate are not expensive and he never eat much and always let a portion in stomach empty while portion sizes in South Asian households are ridiculously big" (male Islamic leader, Birmingham).

Many participants, particularly the younger IRS workers (aged20-40 years), expressed that some South Asian community members and Islamic leaders in the UK have a limited understanding of mosques; using them only for daily ritual worship. On the other hand, Prophet Muhammad's mosque was exemplary, including people from diverse backgrounds, encouraging social and community activities, such as sports, and opportunities for learning languages and community relations. "These days, people have no idea how Prophet Muhammad used his mosque in his time; there were children playing, non-Muslims coming, learnings good manners, discussion on community affairs, and openness to women" (mother, Bradford). We learned that young IRS workers were eager to expand the scope of activities in IRS beyond ritual worshiping and wanted to involve experts on healthy lifestyles visiting frequently and working in partnership with Islamic leaders.

Most participants agreed that Islamic narrative on healthy dietary practices, if disseminated by making it relevant with modern life, can influence people's food habits positively. "If an Imam or a teacher in IRS is saying healthy eating is part of being Muslim, which is true, that will change people" (father, Birmingham). Participants 
shared many examples from Islamic narrative in the form of the sayings of Prophet Muhammad, quotes by Islamic scholars, learning from Islamic practices, and stories for children that, in their view, can be narrated through IRS to encourage dietary behaviour change. "Prophet Muhammad never had two or three dishes in one day and always had one dish a day" (mother, Birmingham). The foods mentioned in Quran like dates, olives, figs, pomegranates, grapes, lentils and honey and many more should be encouraged as a healthy options" (female IRS worker, Bradford). "Prophet Muhammad told us to divide stomach in three parts when we eat; first to be filled with food, second with water, and third to remain empty. The message is to eat less" (female IRS leader, Birmingham). Participants agreed that Quran and other Islamic narrative strongly advocate serving and consumption of modest and not extravagant food. "To eat excessive is haram (forbidden)" (mother, Bradford). Islamic leaders explained that the South Asian community should be educated that to inflict bodily harm is strictly forbidden in Islam and unhealthy dietary habits cause bodily harm in the long run.

All participants also acknowledged that IRS can use Islamic narrative to promote physical activity and healthy sleeping habits. "The Prophet Muhammad has advised us to walk to the mosques and told that every step of walking to mosque has a spiritual merit and reward" (male Islamic leader, Bradford). Islamic leaders said some children come to madrassa to memorise the Quran and they could encourage healthy sleeping habits. Islamic leaders also acknowledged that parents need to be educated not to bring young children to night prayers in the mosque.

\section{The influence of cultural context}

There were clear cultural influences on diet, physical activity and sleeping behaviours that South Asian parents and Islamic leaders viewed as problematic. These were considered targets for obesity prevention interventions.

Diet and cultural context: "Our people are in denial about accepting that their dietary practices are unhealthy and there is a lot of glorification of unhealthy food. We are just foodie people" (mother, Bradford). Research participants perceived a number of unhealthy habits are embedded in South Asian culture, including cooking multiple dishes for meals, over-eating, and unhealthy food choices. There are also cultural perceptions around fat being healthy in children, and many don't view childhood obesity as a problem. "A chubby/plump child is perceived as a healthy child" (female Islamic leader, Birmingham). Parents commented that they receive negative remarks from relatives and community members if their children look slim. "My daughter is a little overweight. Whenever I speak with someone in community about it, they are like "shut up and stop complaining, this is not an issue" (mother, Bradford). Islamic leaders acknowledged that there are no Muslim organisations raising awareness about healthy eating or maintaining a healthy body weight. IRS workers mentioned that they know families where women start making food a month before Ramadan. "Rubbish bin bags are always double in our South Asian streets during Ramadan" (female Islamic leader, Birmingham). "While Prophet Muhammad said to keep one portion of stomach empty when you eat, I was surprised when one child shared this joke that one portion is for food, second for water and third is for dessert" (Male IRS worker, Bradford). Mothers commented that family members and relatives become judgemental and young women are labelled as "untrained" if food is cooked and served using low salt, fat and sugar. Islamic leaders shared that families are pressurised to offer large amounts of food (like a feast) regularly in IRS. 
Gender of a child and physical activity: Cultural taboos among South Asian communities around physical activity in girls, particularly after reaching puberty, was a frequently cited barrier hindering the scope of activity for South Asian girls. This was partly around the practicality of where they could change clothes, but also related to mixing of girls and boys in unsupervised spaces "Physical activity in same class for 5-9 years old boys and girls in IRS is alright with me, but it should be in separate classes for girls when they are 10 years or above this age" (mother, Birmingham). The majority of participants said that they would prefer physical activity for girls in IRS to be conducted by female instructors. As boys and girls attend IRS in separate classes already, most of the research participants maintained that separate physical activity classes can be more acceptable to South Asian communities. However, some parents and Islamic leaders were receptive to the idea of boys and girls taking part in physical activity together in the same session. "If we start physical activity in same space for both boys and girls which I personally think is OK, some community members might say, 'why is an IRS doing it?" (male Islamic leader, Bradford). Islamic leaders maintained that there is diversity within South Asian communities in terms of how they view mixing of sexes in gatherings, "Rather than saying segregated physical activity, I will say same-sex physical activity is more inclusive for the community we are talking about" (male Islamic leader, Bradford). IRS workers shared that more inspirational female sport role models are needed from British Muslim communities to encourage physical activity. "We have got like Amir Khan in boxing and Sir Mohammad Farrah in athletics, but no Muslim female role models" (female IRS worker, Birmingham).

Sleep and sedentary patterns: Research participants indicated that the majority of South Asian Muslim families living in the UK don't maintain healthy sleeping patterns for children. "Poor child is up on his feet since seven/eight o'clock, has a quick breakfast and rush to school, back home and have a quick snack or whatever is available, rush to madrassa and back home in evening, Asian families usually eat late so a child eats around 7-8pm and then straight to sleep, you imagine eating at eight o'clock, then go straight to sleep, when does your body digest that?' (mother, Birmingham). Some parents informed us that children in South Asian families often sleep late resulting in drowsiness in school. In addition to unstructured sleeping patterns, excessive screen time was also discussed as an issue, leading to less time for physical activity. IRS workers related that younger children have recounted watching TV until $9-10 \mathrm{pm}$. Islamic leaders also acknowledged that parents often buy mobile devices for young children and without parental control, these keep them awake till late at night. "I have witnessed some young mothers giving mobile phones to children to make them finish their meal and others using electronic devices as babysitting tools" (Female IRS worker, Bradford).

\section{Practical barriers and facilitators to implementation of an IRS based intervention}

Financial limitations and physical restraints of IRS were mentioned as potential barriers to management allowing health promotion activities. Participants explained that most of the mosques and madrassas are selffunded by attendees, through collections after Friday prayers and on other occasions. Teachers and workers within IRS usually work as unpaid volunteers. Therefore workers may resist taking on additional workload. The buildings used and physical infrastructure of IRS can also act as barriers. Some of the madrassa are in houses, some in small buildings with small classrooms that doesn't provide enough space for physical activities, only few lucky one has massive hall available (Islamic leader, Bradford). Research participants implied that delivery 
of interventions during week days would be a challenge because of limited time and would need to be delivered by complementing madrassa curriculum, over the weekend or by fixing a day during the week.

A potential lever was around collaboration between IRS, schools and the health service. Parents and Islamic leaders related previous instances when there were benefits from collaboration between IRS and other organisations. "The school that my daughter goes to have a madrassa straight after school, so I don't have to take her out for Islamic learning once she is home from school. This just makes it easy" (mother, Bradford). Such a partnership was considered convenient for parents and provides an obvious setting for children to engage in physical activity. Another example was related to collaboration with a CCG: "In past there was a project by Bradford Clinical Commissioning on dental hygiene, Smile with the Prophet, where CCG community health workers provided a pack of toothpaste, toothbrush and some instructions to madrassa. This was a great success for dental health promotion as children, parents and IRS management took part in it enthusiastically" (Islamic leader, Bradford). Partnership with experts was also viewed positively. "Children need to be told other than just from their parents on things like drink plenty of water and avoid fizzy sugary drinks, preferably by a doctor visiting IRS" (father, Birmingham).

\section{Discussion}

We have found that IRS largely have the capacity and are receptive to delivering childhood obesity prevention interventions. Parents were supportive of obesity prevention interventions being delivered by IRS staff or professionals collaborating with IRS. Prevalent behaviours such as unhealthy dietary habits, large portion size, and limited physical activity were deemed contrary to Islamic teachings by all participants. South Asian Muslim parents and Islamic leaders in Bradford and Birmingham considered that reference to Quranic scripture and the example and life of the Prophet Muhammad (as a role model) offer opportunities for teaching children about healthy eating and physical activity. Although there were some reservations about the acceptability of delivering physical activity sessions, particularly for girls, IRS managers/workers were willing to run same-sex sessions. The need for female instructors and role models was highlighted. Other perceived barriers related to time, space and funding constraints. Collaboration with external organisations such as schools and the health service presents potential opportunities.

Mainstream health promotion messages and interventions tend to be uniform and without considering the varying needs and responses of ethnic, religious or other sub-groups (29). The available data on health behaviours and health inequalities is mostly collected on measures like ethnicity or socio-economic status of marginalised groups. The intersectionality of ethnicity and religion and how the Islamic narrative on obesity prevention becomes instrumental in behaviour change for one or more ethnic groups has not been the part of public health recommendations and health promotion interventions. This study addresses the dearth of literature on packaging the intersectionality of religion, ethnicity, and deprivation for complex health interventions targeting high risk groups like South Asian Muslims in the UK. The absence of Islamic narrative in available mainstream health promotion plans and polices targeting South Asian or other Muslim communities may limit the scope of successful delivery of any intervention. The assumptions behind efficiency of biomedical models of health interventions and the generic logic of 'public health' assuming high risk 'publics' as homogenous (30) can be problematic. Co-production of interventions between researchers, policy makers, and 
members of public is more likely to address the high rates of childhood obesity among South Asian children in the UK.

School based interventions for health promotion have concluded that parental involvement is associated with better outcomes (21). Interventions in IRS will involve parents as well as children and therefore have potential for greater effect. Islamic narrative on healthy living combined with healthy lifestyle recommendations by health authorities in the UK could influence behaviour among South Asian communities. Available evidence shows high reach through IRS where most of health promotion interventions are targeting physical activity already $(18,23)$. Our findings support to view IRS in the UK as a progressive force for inculcating obesity prevention behaviours through promotion of a 'healthy belief system' in these high risk groups. By using IRS, evidence based recommendations on physical activity and healthy diet combined with Islamic narrative on healthy living could be disseminated effectively and in an engaging manner to children, parents, families, and communities as a whole system.

We learned that an intervention to promote obesity reduction in IRS should consider the caveats of each setting. An intervention targeting behaviour change for obesity prevention should relate more with the lived experience of members of the public attending IRS. Place based groups in these settings, with involvement of local leaders and IRS staff in intervention delivery could result in uptake of activities and ensure sustainability (23). A toolkit or guideline designed specifically for training IRS staff offering educational and informative material to complement the madrassa curriculum using Islamic narrative on healthy living along with obesity prevention recommendations by NHS, PHE and NICE guidelines could prove to be effective.

\section{Limitations}

We collected data from parents, Islamic leaders, and managers/workers of IRS separately. Mixed focus group discussions may have revealed more insights about the scope of health promotion intervention in IRS. However, this might have presented another challenge of social desirability and less open or frank conversations. Our findings are specific to IRS in areas of large South Asian populations in the UK, but may not reflect the views of South Asian populations in smaller areas.

\section{Conclusion}

IRS are suitable venues for delivery of obesity prevention interventions for South Asian children and other Muslim groups in the UK. Islamic leaders are receptive to this idea of delivering obesity prevention interventions and it is acceptable to parents of children attending IRS. The workers and managers of IRS supported delivering such activities. Intervention will be more acceptable if it is delivered in culturally sensitive and religiously appropriate ways and adapted to each setting. The application of lessons from the life and physical fitness of Prophet Muhammad and Islamic narrative on healthy living could potentially overcome the South Asian cultural context where unhealthy practices around diet and physical activity are prevalent.

\section{Declarations}

Ethics approval and consent to participate: Protocol and informed consent were approved by University of Bradford Research Ethics Committee (E645). 
Consent for publication: Not applicable.

Availability of data and material: Data and materials analysed during this study are available from the corresponding author on reasonable request.

Competing interests: The authors declare that they have no competing interests.

Funding and Disclaimer: This research is funded by National Institute for Health Research, Programme Development Grant Application (RP-DG-1215-10002). The views expressed are those of the author(s) and not necessarily those of the National Institute for Health Research or the Department of Health and Social Care. RM, SD, and SB receive funding from The National Institute for Health Research under its Yorkshire and Humber Applied Research Collaboration.

Authors' contributions: SD wrote the first draft and had the primary responsibility for the final content of the manuscript. SD and LS co-wrote the final manuscript and designed analytical strategy. SD and KR collected the data. PA, SB, and RM commented on the manuscript and revised it critically. SB, LS, RM, PA conceived the study. All other authors read and approved the final manuscript.

Acknowledgements: We are grateful to the Islamic Religious Settings in Bradford and Birmingham, parents of children attending these settings, managers and workers of these settings, and Islamic leaders who took part in this research.

\section{References}

1. Gilliland FD, Berhane K, Islam T, McConnell R, Gauderman WJ, Gilliland SS, et al. Obesity and the risk of newly diagnosed asthma in school-age children. Am J Epidemiol. 2003;158(5):406-15.

2. West J, Santorelli G, Lennon L, O'Connell K, Corkett J, Wright J, et al. Beyond height and weight: a programme of school nurse assessed skinfold measurements from white British and South Asian origin children aged 4-5 years within the Born in Bradford cohort study. BMJ Open [Internet]. 2015 Nov 26;5(11):e008630. Available from: http://bmjopen.bmj.com/lookup/doi/10.1136/bmjopen-2015-008630

3. Whincup PH, Nightingale CM, Owen CG, Rudnicka AR, Gibb I, Mckay CM, et al. Early emergence of ethnic differences in type 2 diabetes precursors in the UK: The child heart and health study in England (CHASE study). PLoS Med. 2010;7(4):1-10. 
4. Office of National Statistics. National Child Measurement Programme: England 2016/2017 school year. London; 2017.

5. Bhopal R, Unwin N, White M, Yallop J, Walker L, Alberti KGMM, et al. Heterogeneity of coronary heart disease risk factors in Indian, Pakistani, Bangladeshi, and European origin populations: Cross sectional study. Br Med J [Internet]. 1999 Jul 24;319(7204):215-20. Available from:

http://www.bmj.com/cgi/doi/10.1136/bmj.319.7204.215

6. Law C, Power C, Graham H, Merrick D. Obesity and health inequalities. Obes Rev. 2007;8(SUPPL. 1):19-22.

7. Gilbert PA, Khokhar S. Changing dietary habits of ethnic groups in Europe and implications for health. Nutr Rev. 2008;66(4):203-15.

8. Sahota P, Gatenby LA, Greenwood DC, Bryant M, Robinson S, Wright J. Ethnic differences in dietary intake at age 12 and 18 months: The Born in Bradford 1000 Study. Public Health Nutr. 2016;19(1):114-22.

9. Harding S, Teyhan A, Maynard MJ, Cruickshank JK. Ethnic differences in overweight and obesity in early adolescence in the MRC DASH study: The role of adolescent and parental lifestyle. Int J Epidemiol. 2008;37(1):162-72.

10. Rawlins E, Baker G, Maynard M, Harding S. Perceptions of healthy eating and physical activity in an ethnically diverse sample of young children and their parents: The DEAL prevention of obesity study. J Hum Nutr Diet. 2013;26(2):132-44.

11. Leung G, Stanner S. Diets of minority ethnic groups in the UK: Influence on chronic disease risk and implications for prevention. Nutr Bull. 2011;36(2):161-98.

12. Hornby-Turner YC, Hampshire KR, Pollard TM. A comparison of physical activity and sedentary behaviour in 9-11 year old British Pakistani and White British girls: a mixed methods study. Int J Behav Nutr Phys Act [Internet]. 2014;11(1):74. Available from: http://ijbnpa.biomedcentral.com/articles/10.1186/1479-5868-1174

13. Pallan M, Parry J, Adab P. Contextual influences on the development of obesity in children: A case study of UK South Asian communities. Prev Med (Baltim) [Internet]. 2012;54(3-4):205-11. Available from: http://dx.doi.org/10.1016/j.ypmed.2012.01.018

14. Falconer CL, Park MH, Croker H, Kessel AS, Saxena S, Viner RM, et al. Can the relationship between ethnicity and obesity-related behaviours among school-aged children be explained by deprivation? A crosssectional study. BMJ Open [Internet]. 2014 Jan;4(1):e003949. Available from: http://bmjopen.bmj.com/lookup/doi/10.1136/bmjopen-2013-003949

15. Duncan MJ, Woodfield L, Al-Nakeeb Y, Nevill AM. Differences in Physical Activity Levels between White and South Asian Children in the United Kingdom. Pediatr Exerc Sci [Internet]. 2008 Aug;20(3):285-91. Available from:

http://www.humankinetics.com/eJournalMedia/pdfs/16086.pdf\%5Cnhttp://ovidsp.ovid.com/ovidweb.cgi? $T=J S \& P A G E=$ reference $\& D=$ emed $8 \& N E W S=N \& A N=2008470463$

16. Brown T, Smith S, Bhopal R, Kasim A, Summerbell C. Diet and physical activity interventions to prevent or treat obesity in south asian children and adults: A systematic review and meta-analysis. Int J Environ Res Public Health. 2015;12(1):566-94.

17. Muslim Council of Britain. Muslims are highly ethnically diverse and not one ethnic ' block .' London; 2016. 
18. Dogra SA. Initial findings of the research on using Islamic religious settings to prevent obesity among South Asian children living in the UK [Internet]. Bradford; 2019. Available from:

https://borninbradford.nhs.uk

19. Esmail A. Should Muslims have faith based health services? Bmj. 2007;334(7584):75.

20. Tomalin E, Sadgrove J, Summers R. Health, faith and therapeutic landscapes: Places of worship as Black, Asian and Minority Ethnic (BAME) public health settings in the United Kingdom. Soc Sci Med [Internet]. 2019;230(February):57-65. Available from: https://doi.org/10.1016/j.socscimed.2019.03.006

21. Brown T, Moore TH, Hooper L, Gao Y, Zayegh A, ljaz S, et al. Interventions for preventing obesity in children. Cochrane Database Syst Rev [Internet]. 2019 Jul 23;2019(7). Available from: http://doi.wiley.com/10.1002/14651858.CD001871.pub4

22. Adab P, Pallan MJ, Cade J, Ekelund U, Barrett T, Daley A, et al. Preventing childhood obesity, phase II feasibility study focusing on South Asians: BEACHeS. BMJ Open [Internet]. 2014 Apr;4(4):e004579. Available from: http://bmjopen.bmj.com/lookup/doi/10.1136/bmjopen-2013-004579

23. Rai KK, Dogra SA, Barber S, Adab P, Summerbell C, Arshad M, et al. A scoping review and systematic mapping of health promotion interventions associated with obesity in Islamic religious settings in the UK. Obes Rev [Internet]. 2019 Sep 5;20(9):1231-61. Available from: https://onlinelibrary.wiley.com/doi/abs/10.1111/obr.12874

24. Ghouri N, Atcha M, Sheikh A. Influence of Islam on smoking among Muslims. BMJ [Internet]. 2006 Feb 4;332(7536):291-4. Available from: http://www.bmj.com/lookup/doi/10.1136/bmj.332.7536.291

25. Ainsworth H, Shah S, Ahmed F, Amos A, Cameron I, Fairhurst C, et al. Muslim communities learning about second-hand smoke (MCLASS): study protocol for a pilot cluster randomised controlled trial. Trials [Internet]. 2013;14(1):295. Available from: http://trialsjournal.biomedcentral.com/articles/10.1186/17456215-14-295

26. Ahmed F, King R. Development and testing of a smoke-free homes intervention with Muslim faith leaders in Leeds, UK. Lancet [Internet]. 2012 Nov;380:S22. Available from: http://dx.doi.org/10.1016/S01406736(13)60378-5

27. Shaw A. Risk and reproductive decisions: British Pakistani couples' responses to genetic counselling. Soc Sci Med [Internet]. 2011;73(1):111-20. Available from: http://dx.doi.org/10.1016/j.socscimed.2011.04.011

28. Braun V, Clarke V. Thematic analysis. In: APA handbook of research methods in psychology, Vol 2: Research designs: Quantitative, qualitative, neuropsychological, and biological [Internet]. Washington: American Psychological Association; 2012. p. 57-71. Available from: http://content.apa.org/books/13620004

29. Salway S, Holman D, Lee C, McGowan V, Ben-Shlomo Y, Saxena S, et al. Transforming the health system for the UK's multiethnic population. BMJ [Internet]. 2020 Feb 11;268(February):m268. Available from: http://dx.doi.org/doi:10.1136/bmj.m268

30. Hinchliffe S, Jackson MA, Wyatt K, Barlow AE, Barreto M, Clare L, et al. Healthy publics: enabling cultures and environments for health. Palgrave Commun [Internet]. 2018;4(1):1-10. Available from:

http://dx.doi.org/10.1057/s41599-018-0113-9

\section{Supplementary Files}


This is a list of supplementary files associated with this preprint. Click to download.

- Appendix1Suggestionsbyparticipants.docx 